\title{
International Marketing Capacities and Export Performance: An Empirical Study of Indochinese Exporting Enterprises
}

\author{
Hoang Nguyen ${ }^{1}$ \\ ${ }^{1}$ Faculty of International Education, Vietnam University of Commerce, Mai Dich, Cau Giay district, Hanoi, \\ Vietnam \\ Correspondence: Hoang Nguyen, Vietnam University of Commerce, Mai Dich, Cau Giay district, Hanoi, \\ Vietnam. Tel: 84-4-3764-3219. E-mail: maycay2001@yahoo.com
}

Received: April 23, 2012 Accepted: May 8, 2012 Online Published: July 25, 2012

doi:10.5539/ijms.v4n4p51 URL: http://dx.doi.org/10.5539/ijms.v4n4p51

\begin{abstract}
The tendency towards globalization, regionalization and the wide and deep integration into the world economy leads to the fact that foreign trading activities has a specially important and decisive position in the entire process of socio-economic development and integration into the regional and global economics of the countries. The role played by foreign trade, including export, thus becomes more essential for those developing countries such as the Indochinese ones (Vietnam, Laos, Cambodia). In the perspective of the resource-based approach, this article aims to analyze the export performance of Indochinese companies. Our findings indicate positive relationships between four international marketing capabilities and exporters' performance. We also propose some measures to improve and optimize the export performance of Indochinese exporting companies.
\end{abstract}

Keywords: international marketing, export performance, Indochina

\section{Introduction}

Export is the driving force and the activity that gives the largest contribution to economic growth rate; export also plays an important role in transforming economic structure, attracting investment, solving the unemployment problem, increasing foreign currency inflows, expanding foreign relations of Indochinese countries. In the period 2001-2010, the proportion of goods and services for export in the GDP of the Indochinese countries increased gradually over years. As to Laos, be the one with the lowest growth rate among the three countries as it was, this country still managed to maintain its regular growth, with export accounted for $28 \%$ of GDP in 2001, till 2010 that was $36 \%$. Cambodia achieved a stable growth rate, too: export accounted for $53 \%$ of GDP in 2001, increased to $66 \%$ in 2008, global economic crisis reduced this to $54 \%$ of GDP in 2010 . The role of export in economic growth was best shown in Vietnam: if in 2001, export value only accounted for $55 \%$ of GDP, then by 2010 , this obtained an impressive increase of $78 \%$. In addition, export also played an important role in transforming economic structure, attracting investment, solving the unemployment problem, increasing foreign currency inflows, expanding foreign relations... of the three Indochinese countries.

Not only playing an important role in national economic development, export is also essential for the existence and development of these three countries. Nevertheless, while participating in international markets, the elements for success in the home market will probably no more appropriate for the enterprises to continue their developments at international markets. So as to be successful in the conditions of the new markets, where competitions are severe, of the playground on which opponents are very strong in terms of resources and financial potential, enterprises should therefore be equipped with sufficient necessary knowledge. One of the elements for the enterprise's success is international marketing capacities; this contributes to creating competitive advantage, guaranteeing operational efficiency for exporters on international markets. Nonetheless, a good deal of limitations can still reveal in international marketing operations of the three Indochinese countries at the present time, as resulted from the negative impact from export preference of the country as a whole in general and of the enterprises in particular. The pressing requirement posed for enterprises in these three countries when engaged in export is to promote their international operations, from that to improve their export performance and contribute to the sustainable development of the exporters and the national economy of each country and the whole region as well.

Quite aware of the important role played by international marketing for the operational efficiency of the entire 
economy in general and of exporting enterprises in particular, we propose to examine the effect of international marketing capacities on export performance. We take the Indochinese companies as case study. Our research aims at analyzing the relationship between international marketing capacities and export performance of Indochinese exporters. Based on the research results, we will discuss their implications for improving the performance of export of the country and the region in general and of international marketing operations of enterprises in particular.

The rest of our article is organized as follows. Section 2 introduces the conceptual and theoretical framework. We then present successively our research method, empirical results and result implications in Sections 3, 4 and 5. We provide some concluding remarks in Section 6.

\section{Conceptual and Theoretical Framework}

\subsection{Basic Concept}

International marketing is the operation which enterprises carry out for the purposes of orienting and meeting the requirements of foreign markets, from that to work out suitable measures to best satisfy such requirements. So, unlike normal (domestic) marketing operations, international marketing applies the rules and methods of normal marketing operations in a creative way under foreign market conditions. As defined by AMA (American Marketing Association), international marketing is a process of planning and organizing the implementation of the 4P-strategy (Product, Price, Provision, Promotion) on a multinational scale so as to fulfill the requirements of local organizations and individuals through exchanges.

Export performance is whether success of failure of the efforts made by an enterprise or a country in bringing its goods and/or services to penetrate the market of other countries. Export performance may be measured through such indicators as sales figures, profits, marketing scales or other subjective measuring tools, customer satisfaction as an example.

\subsection{Resource Based View}

It was often believed by previous marketing researches that: enterprise's export performance was decided by external elements. Accordingly, the external elements that bound enterprises should be adaptable to it. And the successful enterprises were those that had applied a proper marketing strategy, owing to this, they could well adapt themselves to the outside environment and achieve the performance which surpassed the one of other enterprises (Zou and Stan, 1998). The environmental elements usually referred to in researches on export were grouped into the three main ones: features of area of activity, features of export market, and features of domestic market. In reality, however, these researches put aside the enterprise's particularities, which were elements that would have influence on the competitiveness and export performance of the enterprise.

Under the point of view on new approach to resources, corporate resources are the very prerequisites for ensuring competitive edge and performance of the enterprise, not simply the strategies applied and carried out on the market by the resources (Wernerfelt, 1984). This approach enables us to assess not only the export performance of enterprises through their operations (strategies) at international markets but also the advantages of their tangible and intangible resources. The authors, in view of this approach, all believed that it was the resources, not the strategies of exporters, that create competitive edges of exporters.

Anyway, not all corporate resources can provide them with competitive edges. Resources as such must ensure the four features: (1) rare, (2) creating values for enterprise, difficult to be imitated, and difficult to be replaced on the market (Barney, 1991). In general, there are two sorts of resources that can create corporate competitive edge, i.e., assets and capacities (Dierickx et al., 1989). While assets are tangible, then capacity contains intangible dimensions which are very hard for accurate assessing and measuring. Capacity incorporates the skills and knowledge that the enterprise has accumulated in the course of organizing and operating, helping the enterprise coordinate effectively its activities and make full use of its assets (Teece, Pisani and Shuen, 1997). It is the very string that links the various kinds of assets of the enterprise and ensure that they will be exploited in an effective manner. Especially, when capacity creates for the enterprise a status with advantage over the rivals, then they are called strategic resources under the view on resource approach. In the present-day intellectual economy, capacity plays the most important role in helping enterprises survive and develop under the conditions of the domestic market as well as of the international export market.

As a matter of fact, capacity is but the potential with which the enterprise can have competitive edge over the rivals (Barney, 1991). Furthermore, what the enterprise needs is how to achieve prominent performance through its capacities. Porter (1985) thought that cost leadership and differentiation were the two initiators of competitive edge. Low cost may enable exporter to apply a low price, therefrom to increase sales revenue and profit; 
meanwhile product differentiation will make it possible for the enterprise to build up its trademark and image with customers on international markets. In this approach, Conner and Prahalad (1996) developed and presented their point of view on competition based on resources. They thought that capacities and assets were the very researches of the enterprise; both were the constituents that created competitive edge thus helping the enterprise try towards taking the lead in terms of cost leadership or differentiation. Hitt et al. (1997) pointed out that in several cases, enterprises might apply a combined strategy so as to obtain both cost leadership and differentiation.

The relationship between the advantage created by capacities and performance of the enterprise is not only confirmed under the conditions of domestic market but also applicable to export markets for two reasons. First, the Resource Based View works on the supposition about the heterogeneity among enterprises (Barney, 1991): The more heterogeneous the enterprise's resources are, the more important its capacity plays a role for its performance. This differentiation among enterprises become even more serious at international markets, in this article that is exporting markets, since they come from different countries with different cultures. Therefore, capacities of international marketing determine the enterprise's competitive advantage and then influence on its export performance on the international markets. Actually, the marketing capacities of each enterprise are attached in the capacities and knowledge of its employees (Hall, 1993). This prevents other rivals from imitating or makes it difficult for them to acquire, as this is very costly and because of invisible elements originating from the complexity of the exporting markets, from the differences in cultures and geography to which enterprises are confronted. Such markets therefore can meet the two core suppositions of the Resource Based View, i.e., the differentiation in resources and resource immobility. In other words, the theoretical frame of this article is proper for analyzing the relationship between capacities of enterprises and their export performance.

Based on the theoretical framework of export performance, this article focuses more specifically on the international marketing capacities of exporters at international markets. Such capacities, as judged, give positive contributions to the export performance of these enterprises. This choice of ours can be justified for two reasons. First, capacities differ from assets, since they cannot be evaluated exactly with money and are often closely associated with the routine operations and practices of the organization (Conner and Prahalad, 1996; Kogut and Zander, 1996). Second, unlike assets, capacities cannot easily be traded and imitated (Dierickx et al., 1989), since they incorporate tacit knowledge and can only be available through a long period of studying and accumulating (Teece et al., 1997).

Next, by applying the traditional 4P marketing model (Kotler, 2003) to export markets, the theme will concentrate on analyzing the four international marketing capacities, including: product development capacity, evaluation capacity, allocation capacity, and communication capacity. These four capacities represent most of the core elements of the marketing mix that exporters should have and can carry out to create and assert their strategic positions on international exporting markets (Aaker, 1991).

\subsection{Four International Marketing Capacities}

- Product Development Capacity: New product capacity is the exporter's capacity to launch his new products on international markets so as to meet the requirements of such customers, from that to create differential competitive edges for the enterprise. Li and Calantone (1998) pointed out that this capacity was built basing on customer requirements, competitiveness, potential for research and development of the exporter. The characteristics of new products such as quality, reliance, newness, uniqueness... will help promote the image, trade name and capacity of the enterprise in satisfying customer requirements and enable the exporter to make the differentiation of the product against the rivals (Day and Wensley, 1988). According to the model of marketing mix by Kotler (2003), product development capacity was closely associated with competitive edge and had positive influence on the enterprise's performance.

- Pricing Capacity: Is the capacity with which the exporter can carry out and manage effectively evaluating techniques and price strategies in order to face and adapt to challenges from rivals and changes of international customers as well. Pricing capacity shall ensure for the exporting enterprise competitive edge in terms of, most importantly, price on the market, on the other hand, it also creates favourable conditions for the enterprise to control expenses and manage finance effectively. It should be stressed that, effective expense control shall enable the enterprise to create competitive edge against its rivals, hence the low cost advantage.

- Distribution Capacity: Is the capacity by which exporter can provide distributors with prominent supports, from that to establish strong ties with them as well as with customers on the exporting markets. According to Anderson and Coughlan (1987), the exporting markets required that enterprises should have a high level of understanding their customers as well as high level of before and after services. Nevertheless, in actual practices 
on the international markets, gathering exact information about custom requirements was very difficult. In order to gain a competitive edge in terms of product trademark and get feedback from the markets, exporters had to guarantee a close cooperation with export distributors (Porter, 1986).

- Communication Capacity: Communication capacity relates to the exporter's capacity to use and manage in an effective manner the means of communicating marketing to customers. Communication capacity can be implemented at different levels, from concentrating on looking for customers till linking customers and finally linking distribution channels till end-users. Upon concentrating on customers, communication functions as a link to customers by persuading them in respect of price, product peculiarities, warranty, after sale services... Upon concentrating on the targets being organizations, communication capacity should play the role of identifying the market and linking the distribution channels. In communication, feedback is always very important; sharing information and feedback among the parties related will help build up and forecast well the market requirements (Duncan and Moriarty, 1998).

Based on the theoretical framework about international marketing capacity as mentioned above, the theme carries out assessment and experimental test of the role of such elements and their influences on the export performance of the three Indochinese exporting enterprises.

\section{Research Method}

With a view to researching international marketing capacities and the real situation of carrying out and application by Indochinese exporting enterprises on the international markets, the theme employs the combination of the two methods for analyzing literature and interviewing. Specifically, the method for analyzing literature focuses on collecting and treating secondary data as included in reports, overall assessments, analyses by experts, information from workshops, special subject studies relating to the issue under research, documents... in connection with the theme at exporting enterprises of Vietnam, Lao and Cambodia, information from Ministry of Industry and Trade, General Statistics Office, General Department of Customs of the three countries and data from the World Bank.

At the same time, primary data is gathered by an experimental method, i.e., interviewing some typical entrepreneurs of the three Indochinese countries, economists on the issue of export, on the real situation and prospects of international marketing capacities of this enterprise and its influence on the export performance. Interviews were conducted in keeping with an interview guide, and focused on the following:

- Part 1: Requesting the interviewee to introduce about his company and about himself. For enterprise, the necessary information would cover the name, lines of business and export, time and experiences that still remained and had been exported abroad, sales revenue, and the role of export for the enterprise. As to experts, they were asked to introduce themselves.

- $\quad$ Part 2: Entrepreneurs were asked in person about the international marketing capacities researched by this theme. For each capacity, we required judgment on the role played by each capacity and their influence on the export performance. More specifically, we explored deeper into the real situation, difficulties, challenges confronted as well as prospects and solutions which exporting enterprises of the three Indochinese countries would likely to carry out. As to the experts, we focused on their assessments of the exporting markets, the status and prospects of export in the future of the Indochinese exporting enterprises.

- Part 3: We consulted them about their comments on the export performance of each enterprise and the general export performance, particularly through the satisfaction of the enterprise and experts towards the performance in general and of each international marketing capacity in particular.

Data was summed up, analyzed and the research outcomes of the theme were presented in the next part.

\section{Empirical Results}

\subsection{Influences of International Marketing Capacities on the Export Performance}

In the tendency towards profound integration into the world economy, exporting activities play the ever-important role in the economy of the three Indochinese countries. Marketing capacities are being ever improved by enterprises of these three countries so as to promote and improve the performance of export to the world market. Such activities as market research, improving products and strengthening communication... are continuously promoted. According to the outcomes of our analysis of documents and interviews, the real situation of export marketing operations in the relations with the four international marketing capacities are as follows: 
- Evaluation activity: Evaluation activity was applied very flexibly at enterprises of the three countries according to the principle of minimizing cost to create competitive edge in terms of price compared with the products of the some sorts and kinds on the world market. The general assessment of pricing capacity of Indochinese enterprises, according to exporting entrepreneurs and experts, was very well brought into play, in spite of the hindrance caused by the cost of imported materials yet this was compensated by the highly competitive human resources. It can be said that enterprises of Vietnam and Laos made full use of their advantages, i.e., the cheap labour force for reducing costs to a minimum level. This may be regarded as valuable human resources only Vietnam can boast and this is not imitable. To make it hard to be replaced, the governments answer enterprises of the countries set high store of activities for developing high quality human resources to meet the requirements of the countries in general and of enterprises in particular. Nevertheless, this process of minimizing cost is still limited, since the sources of materials imported from abroad are usually very high. On the other hand, goods exported from Indochina still meet with innumerable obstacles with tariff and non-tariff barriers at importing markets.

The reason, as to Vietnam, is that, even is already a member of the WTO, the tariff barrier has not been lifted completely thereby incurring a remarkable tax rate. This keeps input costs at a rather high level thus reducing the competitive edge in terms of price of Vietnamese enterprises. As to Laos, enterprises of this country have to face more problems, since their trade policies have still not actually open yet; cost for importing materials is at a rather high level. Besides, as Laos is not yet a member of the WTO, the tax rate of commodities exported to other countries as well as cost of materials imported from foreign countries are all rather high. Among these three countries, only Cambodian enterprises can have many advantages in terms of import-export tax rates. At the same time, unlike Laos and Vietnam, Cambodia has had access to the United States fairly early through trade agreements (the United States is the world leading importer and exporter); Cambodian goods therefore have competitive edge in terms of price at export markets.

In the coming time, when the world economy is still heavily impacted by crisis, so as to maintain their competitiveness in terms of price, the Indochinese enterprises should take the initiative in seeking measures for effective financial management as well as to reduce unnecessary expenses to improve the quality of export operation in general and of international marketing in particular.

- Product development activities: Product research and development is an indispensable operation in international marketing. Products should always be improved, even replaced by more preeminent to meet international customer requirements. It needs to be stressed that while engaged in the export market, Indochinese enterprises shall have to be confronted with much more severe competition in practice then in their domestic and the Indochinese or ASEAN markets, with the involvement of rivals big and strong in size and in fame as well. On the other hand, product development also helps create the differentiation for the enterprise's product with more preeminent peculiarities which can hardly be imitated by the rivals. Though aware of the importance of this operation, according to export experts, there still remain many limitations in the Indochinese enterprises' product development capacity. The reason lies within the level of science and technology in general and of these enterprises in particular is still behind that of the developed and other newly arising countries. Also, the majority of enterprises as such, out of their poor strategies, turn to pursuit opportunist point of view, resorting to human resources as their main advantage in respect of price.

The recent time saw changes in the situation as mentioned above in numerous Vietnamese and Lao enterprises. Some set up departments or centers for product research and development so as to provide the export market with best products, other bravely invested in modern production lines thus helping minimize the costs while still assure, even improve their product quality.

- Product distribution activities: According to the enterprises taking part in interviews, they always place emphasis on establishing long-term relations with distribution channels, on the one hand to ensure export performance, on the other to ensure before and after service customer caring operations at international markets. Almost all Indochinese enterprises opt to the form of exporting commodities direct to foreign importers or selling direct to customers. This situation reveals the very limited capacity in distributing their products on international markets of Vietnamese, Lao and Cambodian enterprise. The main reason for this is closely associated with their capacity for orienting strategies, trade and non-trade barriers, and especially the difference in language, culture and geography.

The advantage of using intermediate distribution channels is the possibility to make use of the infrastructure, knowledge of markets, tastes and shopping habits of export market customers. In this view, Indochinese enterprises, particularly Vietnamese ones, embarked on establishing, maintaining prestige and trust with their 
customers. However, there is a limitation in the use of this distribution channel, namely the enterprises cannot contact direct their end-users but through importers. Another weakness is the dependence of the three country's enterprises on importers when they fail to have direct contacts with their end-users. Any change of customer requirement or inside importers may also have negative in force on production activities and export performance.

- Product marketing communication activities: The enterprises taking part in interviews said that they were all deeply aware of the role played by communication in their operation performance at export markets. They usually provided the representatives and importers with product samples, catalogues, advertisements or met in person to discuss, introduce the enterprises and their range of products. In addition, some other kinds of the mass media were selected, for example, for advertizing on specialized magazines, participating in exhibitions, introducing products in fraternal countries. Survey findings showed that Vietnamese enterprises proved to be more activity in this aspect. Yet, as the general resultant impact on the distribution capacity focusing on importing partners, activities of marketing, promoting products till end-users were not much applied by Indochinese enterprises. According to some entrepreneurs, the question lies in the costs of design, advertisements which were too high whereas the size of exporting enterprises were still limited, plus the culture and language barriers. Hence, also according to them, the Governments and associations should assign the charge of such issue to Indochinese enterprises rather than to each individual one.

Generally speaking, notwithstanding some problems, in recent years, the international marketing capacity of Indochinese enterprises has been improved considerably thus improving substantially the export performance of these Indochinese countries as a whole, as shown in the following table:

Table 1. Proportion of Export in GDP

\begin{tabular}{lllllllllll}
\hline & $\mathbf{2 0 0 1}$ & $\mathbf{2 0 0 2}$ & $\mathbf{2 0 0 3}$ & $\mathbf{2 0 0 4}$ & $\mathbf{2 0 0 5}$ & $\mathbf{2 0 0 6}$ & $\mathbf{2 0 0 7}$ & $\mathbf{2 0 0 8}$ & $\mathbf{2 0 0 9}$ & $\mathbf{2 0 1 0}$ \\
\hline Vietnam & 55 & 57 & 59 & 66 & 69 & 74 & 77 & 78 & 68 & 78 \\
Lao & 28 & 28 & 28 & 29 & 34 & 40 & 34 & 32 & 30 & 36 \\
Cambodia & 53 & 54 & 57 & 64 & 64 & 69 & 65 & 66 & 49 & 54 \\
\hline
\end{tabular}

Source: World Bank Database 2011 (http://data.worldbank.org/)

According to the World Bank Database, we can observe that the export performance of the three Indochinese countries is on an increase and playing a bigger and bigger role in national economic development. Especially for Vietnam, the growth of export was continuous and suitable per year. Till 2001, if export value only accounted for $55 \%$ of GDP, then this figure grew through years and reached the top value in 2008 up to $78 \%$. In 2009 , impacted by the global crisis, this rate decreased, but still reached $68 \%$. In 2010, despite the difficult economic situations of the home country and the world, the measures for promotion, including international marketing capacities, brought Vietnam back to its momentums of growth and continue to reach a high datum-point of $78 \%$ of GDP nationwide.

Export also plays a major role in Cambodia's economic development when export value often accounts for over $50 \%$ of this country's GDP. Owing to its early trade relations with the United States which serve as a gateway for export to other markets, in 2001, export value in GDP of Cambodia reached 53\%. This rate increased gradually through years and to the peak of $69 \%$ in 2006. The export markets for Cambodian enterprises showed signs of standstill during 2007-2009 under the impact of the financial crisis; in 2009, the rate of export in GDP of Cambodia fell to 49\%. In 2010, however, it showed signs of recovery and made up 54\% of this country's GDP.

Unlike Vietnam and Cambodia, the rate of export in GDP of Laos increased stably. Anyway, the role of export and export performance of this country was not yet high, only accounting for one third of GDP. This imposed challenge to Lao exporters that they must propose new approaches to make export one of the main driving forces for economic growth in Laos.

\subsection{Benefits and Costs of Export Marketing}

Advantages, as a whole the openness of the economy and the expansion of foreign trade of the Indochinese Governments have brought about many advantages for international marketing activities of these three country's enterprises. Enterprises can have access to a larger number of markets, from that to have marketing strategies more suitable for each market. The processes of globalization, regionalization and liberalization of trade also create advantages for enterprises when they can easily access and gather information on the markets, international customers, as well as access to the advanced and modern technologies of the world. Also, by 
participating in associations and organizations such as ASEAN, WTO, Indochinese enterprises will avoid some tax rate and non-tax rate barriers imposed on exports to international markets or imported materials, so as to reduce costs and strengthen competitiveness.

The development of research on marketing also help Indochinese enterprises have a broader range for selecting and carrying out activities of international marketing. Instead of the traditional marketing modes, enterprises nowadays can apply some new ones, relationship marketing for example, to suit better the real conditions. The development of science and technology such as the Internet, social websites will give positive supports to exporting enterprises in international marketing operations to improve export performance.

Apart from the advantages above, there still remain some disadvantages to which enterprises of the three countries will have to be confronted when carrying out their marketing operations at international markets. Typically:

- The cultural, political and economic distances at exporting markets make it hard for enterprises to get access to customers.

- The rival competitions that come from their rivals on the international markets, as these have great potential and many years operating in international marketing.

- The human resources in charge of marketing in enterprises have not been trained systematically and have few experiences in international marketing.

- Particularly for Laos, as this country has not yet joined the WTO, in accessing foreign markets, it has to be confronted with various kinds of tax rate and non-tax rate barriers.

Prospects for application and development of international marketing activities of Indochinese enterprises, in the coming time, it is certain that such activities will be promoted to improve export performance. In so doing, enterprises will speed up their international marketing activities and improve their international marketing capacities. Enterprises also tend to use new marketing approaches or in combination with professional marketing partners at international markets so as to carry out their marketing strategies in the most effective manner, minimizing the restrictions on marketing capacities. Furthermore, that Laos is going to become a member of the WTO will assist a lot the export marketing activities of this country.

\section{Result Implications}

Based on the findings of research on the real situation of international marketing and effect of the respective capacities on the export performance of Indochinese enterprises, the theme proposes several basic solutions to further promote marketing activities of exporting enterprises in Vietnam, Lao and Cambodia, thus helping improve the export performance of the region as a whole. Groups of solutions include:

\subsection{Proposals for Indochinese Exporting Enterprises}

First, conducting wide and deep survey of the export markets. This operation will help Indochinese enterprises have a more specific grasp of international markets, so as to prevent from possible risks and improve the performance of international marketing activities for enterprises. Export market research should focus on such issues as: potential of import markets, tastes, requirements, culture and customs of each market, modes of transaction, entering into contract on payment and spending of each market, general and several international regulations of each international market, distribution channels preferred to be selected by customers at each market, situations of competitions and rivals, most effective mass media on each market... From such researches, Indochinese exporting enterprises shall be able to draw up the most effective and suitable international marketing strategy for each market, particularly, attention should be paid to the channels that have direct contacts with end-users of enterprises.

Second, improving capacities of services or department in charge of international marketing. Enterprises should establish a professional international marketing section. In practice, this activity is very complicated, and now this will be even more complicated once enterprises are involved in international markets, since being there, they will find themselves confronted by more severely competitive rivals due to differences in culture, politics, environment, religion, etc. of international customers. A solution which is good and in order for Indochinese exporting enterprises is to hire professional marketing companies at the international markets where they are involved in export to take the charge of advising and carrying out marketing strategies in specific locality. This will enable them to make use of the capacities and advantages of such professional marketing companies, and since these are local enterprises, they will have the steady knowledge of the local market.

Third, Indochinese exporting enterprises should bring into play their product distribution capacity based on 
establishing sustainable cooperation relations with exporting partners. According to the entrepreneurs taking part in the interviews, the trust among partners is the prerequisite that enables exporting enterprises of Vietnam, Laos, and Cambodia to bring their commodities to penetrate into international markets. This is also a foundation for establishing long-term strategic cooperation relations for mutual benefits of the parties and helping improve the export performance of Indochinese enterprises. In the context of global competition today, relations are also an important force to create competitive edge for exporting enterprises. If managing to establish good relations with importers, enterprises will have an advantage in market research through the information as shared by partners to promote the image, to distribute goods and to access customers easier.

Fourth, improving quality of export products and supporting services. It is product that is the most important element for establishing and maintaining trust with importing partners, and with end-users of enterprises as well. Because it, or the uses or utilities it brings about, is the value they expect to receive. For that reason, Indochinese exporting enterprises should unceasingly develop their product development capacity to product products that are more preeminent in both particularities and patterns, and services to meet the requirements of partners and internal standards. Promoting product-service development and improvement capacity will make it possible for enterprises to obtain differentiation advantage over the rivals' products, and the enterprises can achieve the export performance as desired.

Fifth, strengthening trademark promotion activities. Almost all the Indochinese taking part in the interviews acknowledged that the fames established by them at international markets were still modest. This would influence their international marketing strategies and result in the fact the exporting performance unmatched with the potential. Exporting enterprises therefore should strengthen the promotion of their image and trademark on international markets. There are a wide range of means for promoting the enterprises, such as the Internet, television, newspapers, radio, etc. Nonetheless, according to us, in order to establish trust with the target customers as enterprises, exporting enterprises of Vietnam, Laos, and Cambodia should use specialized magazines, participate in international exhibitions and trade fairs to introduce their products and promote their trade names.

\subsection{Proposals with the Government and Agencies Concerned}

Government always plays a very essential role in the operations of enterprises. For export activities, the Government's policies on foreign trade are characterized by orientation and have decisive influences. Accordingly, to promote international marketing capacities, from that to improve export performance of the entire economy as a whole, the Governments of the Indochinese countries should:

First, strengthening diplomatic, trading activities with countries over the world to make it possible for enterprises to participate in these international markets. The Governments of Vietnam, Lao and Cambodia should therefore be more active by participating in agreements on liberalization of trade to create favourable conditions for commodities from other countries to be imported into the Indochina (including production materials) and help keep enterprises from tax rate and non-tax rate barriers when exporting goods and services.

Second, the Governments of Vietnam, Lao and Cambodia should draw up and implement drastically policies as well as the legal environment in general to speed up export activities of enterprises, making it possible for them to get access to international markets. Specifically, the Governments of the three countries should support enterprises in terms of information, infrastructure development, distribution system construction and consumption market expansion through the embassies or agencies in charge of trade in other countries. Such support will be of special importance for enterprises to know about the markets and partners on international markets.

Third, the Governments of the three countries and agencies concerned should organize various activities for trade promotion, trade fairs and contacts so as to learn about, exchange and introduce among exporting enterprises with foreign partners to further strengthen the co-operation relations among the parties. Activities as such will be a test of trust of Indochinese enterprises, as guaranteed by the Governments of the three countries before foreign partners, from that to assist enterprises in promoting their trade names and improving export performance. For the Lao Government in particular, the process of officially joining the WTO should strongly be speeded up so that more favourable conditions shall be created for enterprises to participate in the export market.

\section{Conclusion}

Development of internal economic relations is indispensable in the period of wide and deep integration into the world economy as well as in the trade liberalization process of the Indochinese countries. In this development, the radical influences of international marketing are undeniable. This theme shows that international marketing 
capacities of the Vietnamese, Lao and Cambodian enterprises have positive influences on their export performance. Export activities are conditions for promoting the economic growth at a high rate, for increasing national income, and one of the premises for the Indochinese countries to carry out industrialization and modernization.

Nevertheless, due to some objective factors and their very own difficulties, the real situation of the international marketing capacities of Vietnamese, Lao and Cambodian enterprises still reveal many limitations, particularly the capacities for product development, distribution and promotion. Pricing capacity has been rated fairly good, but this lies chiefly on the abundant and cheap human resources of the three Indochinese countries. To improve this situation, there should be the combined action of enterprises and Governments in the region to further enhance enterprises' international marketing capacities, from that to improve the export performance and promotion of the trade names of the three Indochinese countries of Vietnam, Lao and Cambodia.

\section{References}

Aaker, David A. (1091). Building Brand Equity. New York: The Free Press.

Anderson, Erin \& Anne T. Coughlan. (1987). International Market and Expansion via Independent or Integrated Channels of Distribution. Journal of Marketing, 51(January). 71-82. http://dx.doi.org/10.2307/1251145

Barney, Jay B. (1991). Firm Resources and Sustained Competitive Advantage. Journal of Management, 17, 99-120. http://dx.doi.org/10.1177/014920639101700108

Conner, Kathleen R., \& C. K. Prahalad. (1996). A Resource Based Theory of the Firm: Knowledge Versus Opportunism. Organization Science, 7(5), 477-501. http://dx.doi.org/10.1287/orsc.7.5.477

Day, George S., \& Robin Wensley. (1988). Assessing Advantage: A Frame work for Diagnosing Competitive Superiority. Journal of Marketing, 52(April), 1-20. http://dx.doi.org/10.2307/1251261

Dierickx, Ingernar, Karel Cool \& Jay, B. Barney. (1989). Asset Stock Accumulation and Sustainability of Competitive Advantage. Management Science, 35(12), 1504-1511. http://dx.doi.org/10.1287/mnsc.35.12.1504

Duncan, Tom \& Sandra, E. Moriarty. (1908). A Communication- Based Marketing Model for Managing Relationships. Journal of Marketing, 62(April), 1-13. http://dx.doi.org/10.2307/1252157

Hall, Richard. (1993). A Framework Linking Intangible Resources and Capabilities to Sustainable Competitive Advantage. Strategic Management Journal, 14(8), 607-618. http://dx.doi.org/10.1002/smj.4250140804

Hitt, Michael A., R. Duane Ireland \& Robert, E. Hoskisson. (1997). Strategic Management: Competitiveness and Globalization. St. Paul, MN: West Publishing.

Kogut, Bruce \& Lido Zander. (1996). What Firms Do? Coordination, Identity, and Learning. Organization Science, 7(5), 502-518. http://dx.doi.org/10.1287/orsc.7.5.502

Kotler, P. (2003). Marketing Management (11th ed.). Upper Saddle River, NJ: Prentice-Hall.

Li, Tiger \& Roger, J. Calantone. (1998). The Impact of Market Knowledge Competence on New Product Advantage: Conceptualization and Empirical Examination. Journal of Marketing, 62(October), 13-29. http://dx.doi.org/10.2307/1252284

Porter, Michael. (1985). Competitive Advantage. New York: The Free Press.

Teece, David, G. Pisani \& Shuen, A. (1997). Dynamic capabilities and strategic management. Strategic $\begin{array}{llll}\text { Management Journal, } & \text { 18(7), }\end{array}$ http://dx.doi.org/10.1002/(SICI)1097-0266(199708)18:7<509::AID-SMJ882>3.0.CO;2-Z

Wernerfelt, Birger. (1984). A Resource Based View Of the Firm. Strategic Management Journal, 5(2), 171-80. http://dx.doi.org/10.1002/smj.4250050207

Zou, Shaoming \& Stan, S. (1998). The Determinants of Export Performance: A Review of the Empirical Literature Between 1987-1997. International Marketing Review, 15(5), 333-56. http://dx.doi.org/10.1108/02651339810236290 